\title{
A Proposed Research Framework for Modeling of Academic Information System in Higher Education Institution toward Education 3.0
}

\author{
H. P. Utomo, A.T. Bon, M. Hendayun
}

\begin{abstract}
Most of modeling in information system used case study. The academic information system also can use the case study method. In a higher education institution who has implemented the Education 3.0 concept, the modeling of academic information system must be combined the method with a suitable framework with Education 3.0 concept. This research will propose the most suitable research framework for modeling of academic information system in higher education institution who has implemented Education 3.0 concept.
\end{abstract}

Index Terms:.

\section{INTRODUCTION}

Research in modeling of information systems has been carried out by the researchers. Various kinds of methodology have been used. There are quantitative as practiced by [1] and [2]. There are also qualitative as practiced by [3] and [4]. Those used qualitative methods, mostly using case studies in their research. A case study is particularly useful in researching issues related to sustainability and institutional systems [5].

In addition to the above method, researchers also use a framework or a model that has been created by other researchers. A framework or model must meet international standards and have been widely used by researchers in their research [6]. This paper will discuss the suitable research framework for modeling of academic information system (AIS) in higher education institution (HEI) toward Education 3.0.

\section{LITERATURE REVIEW}

\section{A. Information System Modeling} support HEIs development. Continual improvement requires the institutions' positioning with regard to its IT capabilities and the quality of its services. To manage IS, HEIs must have a model as instrument for knowing a better positioning of the organization and help find better solutions for change [7]. Moreover, [4] describe that a model can be a basis of an integrated system that overcomes much of the problems.

Revised Manuscript Received on April 25, 2019.

H. P. Utomo, Faculty of Engineering, University of Langlangbuana, Bandung, Indonesia.

A.T. Bon, Faculty of Technology Management and Business, Universiti Tun Hussein Onn Malaysia, Johor, Malaysia.

M. Hendayun, Faculty of Engineering, University of Langlangbuana, Bandung, Indonesia.
Information system (IS) always need improvement to

A model should be developed based on the internationally recognized standards and the model could be used as an action guideline for HEIs to change their IS [6]. Both of [6] and [7] studies have proved that a model is an important instrument if the institutions want to change or transform their existing IS.

\section{B. Academic Information System}

The academic information system (AIS) is software intended to process the academic data of an educational institution. AIS in higher education institutions (HEIs) are generally used to manage the student academic data starting from registration, plan their study and to look at the study result. Most of the HEIs use web-based AIS connected to the intranet or internet [8]. The study mentioned the AIS only used for administrative purposes. The users of AIS from this study only student and administration staff. From [9] study, AIS refer to a set of systems and activities that are used to organize, to process, and to use information as a source within an HEI. The output of the information resulted from this system will deliver information to the leaders or the decision makers that can be categorized in different utilization and different purposes. AIS in this study not only used for administrative purposes but also used by leaders of the institution to help them make a decision for institution development. The AIS used by students, lecturer, administration staff and executive. An academic information system has to cater to the needs of students, faculty and administrative staff [10]. The study compares the AIS in three different HEIs. The study found that AIS mostly have same procedure and function. Hence, they also suggested AIS must be flexible to development. This helps the system to remain up to date and provides better functionality with changing technology and needs of the users. From the facts above, current use of AIS in higher education institutions mostly for administrative process and support the decision maker. The current users also limited to lecturers, students, administration staff and executive leader. 


\section{A Proposed Research Framework for Modeling of Academic Information System in Higher Education Institution toward Education 3.0}

\section{Education 3.0}

According to [11], Education 3.0 is characterized by rich, cross institutional, cross cultural educational opportunities within which the learners themselves play a key role as creators

of knowledge artifacts that are shared, and where social networking and social benefits outside the immediate scope of activity play a strong role. The distinction between artifacts, people and process become blurred, as do distinctions of space and time. In Education 3.0, students are empowered to produce, not only to consume the knowledge [12]. As in Figure 1, Education 3.0 is made possible by Education 2.0 which is internet-enabled learning, and by centuries of experience with memorization in Education 1.0. Education 2.0 begins the transition to a new educational paradigm based on knowledge production and innovation production, the appropriate engines for viable 21 st-century economies. Education 3.0 is qualitatively different incarnations that build upon Education 2.0 information sourcing capabilities and, to a lesser extent, the memorization habits of Education 1.0 [13].

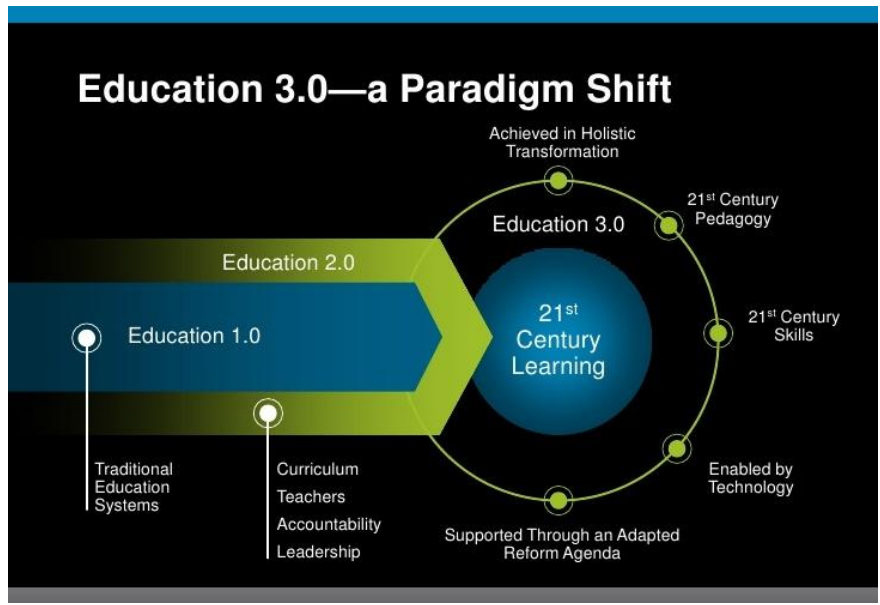

Fig. 1. Education 3.0 paradigm [13]

\section{METHODOLOGY}

This paper used the previous researches and publications to get the most suitable research framework for modeling the academic information system in higher education institution toward Education 3.0. This paper begins with the most used method in modeling of information system, then analyze the chosen research design and adapt the most suitable framework with the AIS and Education 3.0.

\section{THE PROPOSED RESEARCH FRAMEWORK}

From the previous research by [14], the research used case study method. Therefore, the research design will follow case study method research design. Research design is a process creating a blueprint of the activities to take in order to satisfactorily answer the research questions identified before [15]. According to [5], research design is a logical plan for getting from here to there, where here may be defined as the initial set of questions to be answered, and there is some set of conclusions (answers) about these questions.

There are two methods will be adapted and collaborated in this research. The first is case study method by [5] as shown in Figure 2. The method consists three (3) main phases: (1) define and design, (2) prepare, collect and analyze, and (3) analyze and conclude. This research will adapt some detail process in each phase. And the next method is from [16] as shown in Figure 3.

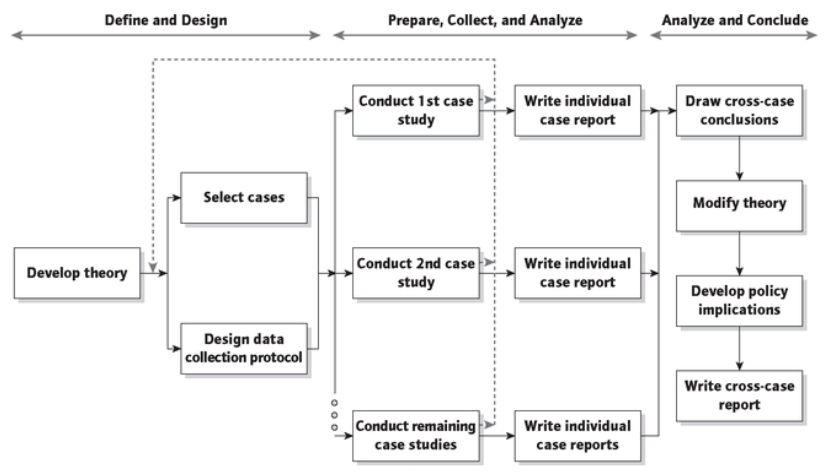

Fig. 2. Case study method [5]

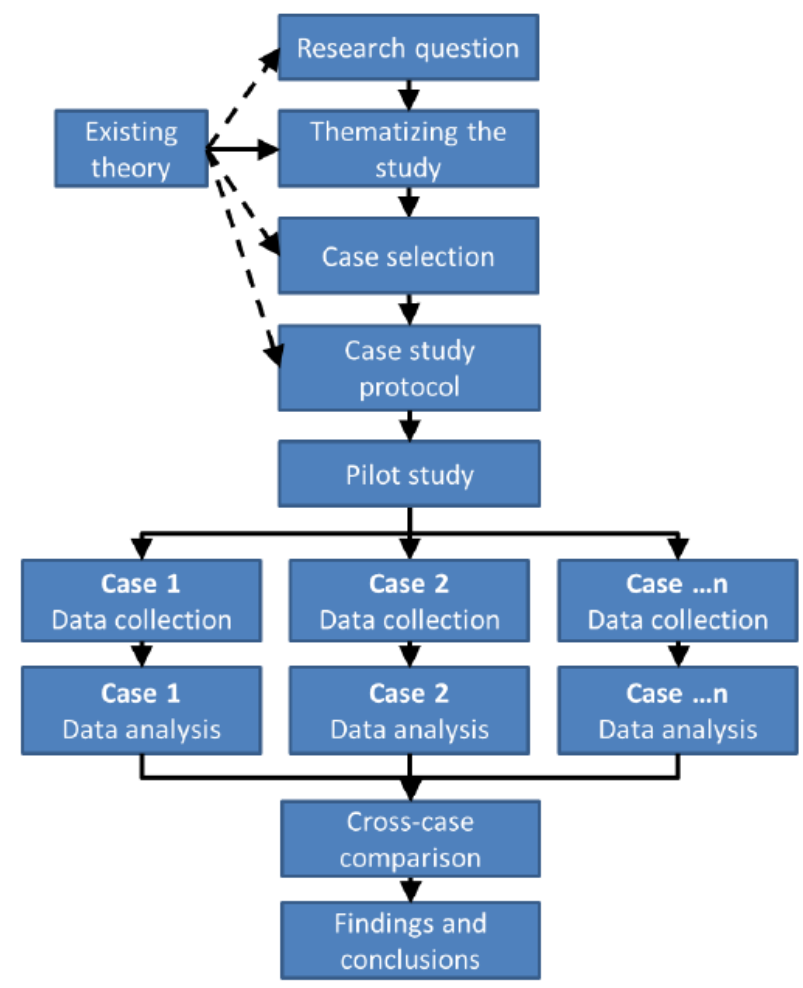

Fig. 3. Case study research [16]

The method by [16] detailed the stages in doing case study research. This research also will adapt some steps and combine it with [5] method. Both of methods show an example for multiple-case study. For single-case study, the method will be similar steps. From both methods above, this research is designing a research framework as shown in Figure 4.

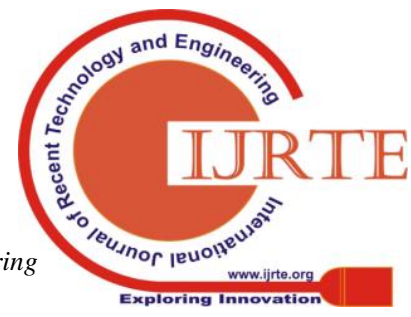




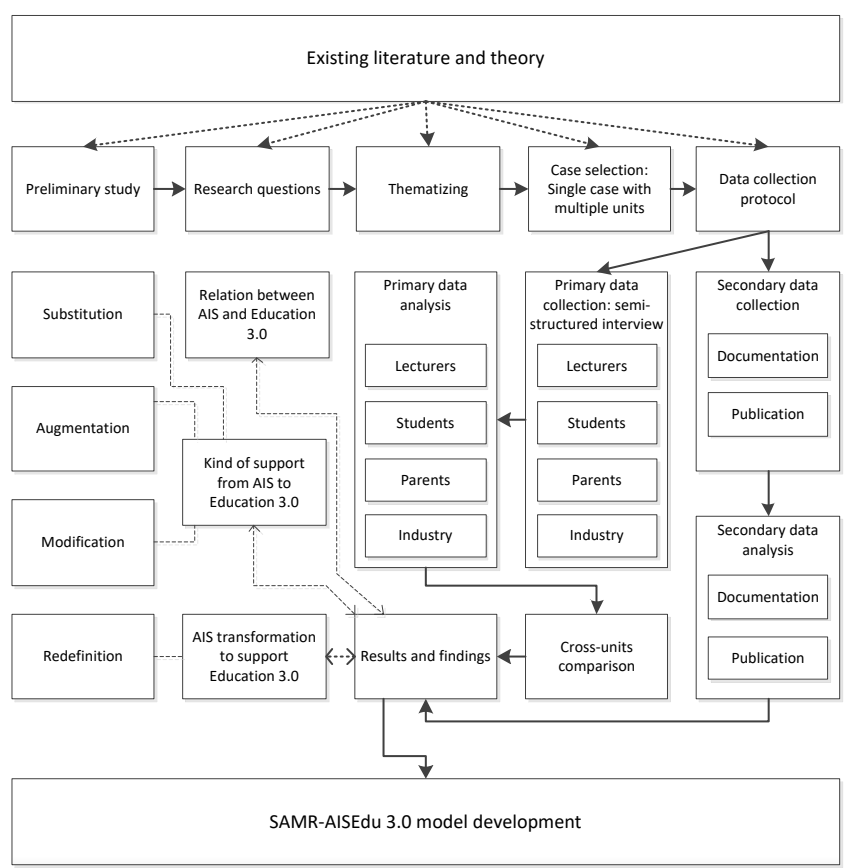

Fig. 4. The proposed research framework

The research will conduct ten (12) stages: (1) existing literature and theory, (2) preliminary study, (3) research questions, (4) thematizing, (5) case selection, (6) data collection protocol, (6) secondary data collection, (7) secondary data analysis, (8) primary data collection, (9) primary data analysis, (10) cross-units comparison, (11) results and findings, and (12) model development.

The first stage is to review existing literature and theory. This stage adapted from [16]. This stage studies the related previous study and theory of AIS in HEIs, Education 3.0, and related framework and model. The sources are from research publication (journal, proceeding), books, and media publication (presentation, video). This stage will support all the next stages.

The second stage is conducted a preliminary study. Preliminary study will explore both substantive topic and method issues. Although such a study will not always be feasible, it can help to sharpen the focus of your research as well as ensure that your intended field procedures are effective [5]. It also helps detect potential problems in your research design and/or instrumentation (e.g., whether the questions asked is intelligible to the targeted sample), and to ensure that the measurement instruments used in the study are reliable and valid measures of the constructs of interest [15]. The aim of this study is to find the real problems faced by AIS users in HEI when Education 3.0 has been implemented. This study also collects problems and hopes from parents of students and industry because they were part of the characteristics of Education 3.0.

The third stage is to define and select research questions based on problem and previous study. Research questions dealing with a specific behaviour, event, or phenomena of interest. Research questions are specific questions about a behaviour, event, or phenomena of interest that you wish to seek answers for in your research $[15,16]$.

The fourth stage is the matizing. This stage is to recognize that prior theory may be used in various ways in case study research [17]. Theory is commonly used in one of three ways in case study research: (1) as initial guide to design and data collection, (2) as part of iterative process in data collection and analysis, and (3) as final product of the research [16]. According to [18], Substitution Augmentation Modification Redefinition (SAMR) framework by [19] adapted as conceptual framework for this research. The research questions will be linkage to SAMR, then will be compare with results and findings, and then the model development will be based on this results.

The fifth stage is to select case. Case selection will be concern in use single-case or multiple-case. According to [5], single-case design is appropriate when the case is representative of a situation or reveals a situation, and multiple-case design is particularly relevant for replication and comparing different study. Researcher also must choose case study typologies between holistic and embedded case study. Analysis in holistic case study is based on the system approach of a phenomenon and useful when no sub-unit can be identified. Otherwise, analysis in embedded case study is focused on sub-units of specific phenomenon and useful to put into perspective the holistic illusion [5]. This research will use Universitas Langlangbuana (UNLA) as case study. The case will be embedded single-case study. UNLA also can be a representative of a situation in this research. UNLA has implemented AIS called Sistem Informasi Akademik (SIAk) and also has implemented Education 3.0 principle in their learning process. The embedded design chosen because we have to get perspective from different type of users. Current and prospective users will be the unit of analysis.

The sixth stage is to prepare data collection protocol. Data collection protocol contains procedure and instrument that will be used in collecting data [16]. The procedure includes how to gain access, how to capture data, and time plan for data collection. The instrument includes data collection and analysis method [16]. Data will be collected through semi-structured interview and documentation. Semi-structured interview still guided by a script, but interesting issues can be explored in more depth and get good balance between richness and replicability [20]. To gain access the data, we must have permission from the institution, and then capture the data using voice recorder and digital camera.

The next stage is to collect data. Data collection will be conducted if the data collection protocol has been completed. First we will get documentation and publication data from institution and then we will conduct interview session with the unit of analysis. We will interview lecturer, student, parent of student and industry. For each unit we will choose five (5) respondents as initial interview. According to [21] and [22], the number of respondents in case study depends on the research itself. Their study suggests to do data analysis may follow or overlap with data collection. Overlapping data collection and analysis has the advantage of adjusting the data collection process based on themes emerging from data analysis, or to further probe into these themes. The collecting data may stop if there is no longer anything new or already reach saturation level. 


\section{A Proposed Research Framework for Modeling of Academic Information System in Higher Education Institution toward Education 3.0}

8. E. Utami and S. Raharjo, "Database Security Model In The Academic Information System", International Journal of Security and Its Applications, vol. 8, no. 3, pp. 163-174, 2014.

The next stage is data analysis. This stage will examine emergent concepts separately at each case units and patterns between these concepts to generate an initial theory of the problem of interest. The researcher can interview data subjectively to "make sense" of the research problem in conjunction with using her personal observations or experience at the case site [15]. The analysis of qualitative data usually moves through five phases. They are compiling, disassembling, reassembling, interpreting and concluding [23]. Computer software is available to assist in the entire analysis process. One risk in using software is the added attention needed to follow the software's procedures and terminology.

The next stage is cross-units comparison. This stage will be conducted after the analysis of each unit has been done. This stage will look for similar concepts and patterns between different units, ignoring contextual differences that may lead to idiosyncratic conclusions. Such patterns may be used for validating the initial theory, or for refining it to develop a more inclusive and generalizable theory [15, 23] This stage will lead to the results and findings stage. We will cross-check the results and findings with research questions and SAMR. The results will be used in final stage to develop SAMR-AIS-Edu 3.0 model.

\section{CONCLUSION}

Based on previous studies, most of researchers in modeling of academic information system used case study method. Their research design followed the method and adapted based on the case they used. The facts above lead this paper to choose the research design from the case study method as the chosen research framework. The proposed research framework will be use as a guideline in modeling of AIS in HEI toward Education 3.0. This research framework will be helpful to the researchers in information system and used case study as their method.

\section{REFERENCES}

1. M. Leh, S. Bajwa and I. Chaubey, "Impact of Land Use Change On Erosion Risk: An Integrated Remote Sensing, Geographic Information System and Modeling Methodology", Land Degr. \& Dev, vol. 24, no. 5, pp. 409-421, 2013.

2. A.M. Castronova, J.L. Goodall and M.B. Ercan, "Integrated Modeling Within A Hydrologic Information System: An OpenMI Based Approach", Env. Mod. \& Soft, vol. 39, pp. 263-273, 2013.

3. W.H. Utomo and T. Wellem, "Modeling of Business Process Management of Academic Affair Information System", International Journal of Computer Applications, vol. 64, no 16, pp. 47-53, 2013.

4. S.A. Mokhtar, S.M.S. Anuar, and S. Puteh, "Information System Model for The Measurement of Learning Outcome Attainment", In 2014 4th Int. Conf. on Eng. Tech. and Technop. (ICE2T), 37-40, 2014.

5. R.K. Yin, Case study research: Design and methods, London: Sage publications, 2009.

6. M. Solar, J. Sabattin and V. Parada, "A Maturity Model for Assessing The Use of ICT In School Education”, Journal of Educational Technology \& Society, vol. 16, no. 1, pp. 206-218, 2013.

7. J. Becker, R. Knackstedt and J. Pöppelbuß, "Developing Maturity Models for IT Management", Business \& Information Systems Engineering, vol. 1, no. 3, pp. 213-222.

E. Indrayani, Management of Academic Information System (AIS) at Higher Education In The City of Bandung", Procedia - Social Behavior Science, vol. 103, pp. 628-636, 2013.

10. B.A. Alyoubi and M.J. Arif, "A Comparative Study Between The Academic Information System of King Abdulaziz University and Other Saudi Arabia Universities", Life Science Journal, vol. 11, pp. 261-275, 2014.

11. D. Keats and J. P. Schmidt, "The Genesis and Emergence of Education 3.0 In Higher Education and Its Potential for Africa", First. Monday, vol. 12, no. 3, 2007.

12. J. Gerstein, "Moving from Education 1.0 Through Education 2.0 Towards Education 3.0", Educational Technology Faculty Publications and Presentations., 2014, (Boise: Department of Educational Technology, BSU).

13. M. Stevenson, P. Cevenini, I. Temple, R. Halkett and R. Patton, 2011 [cited 20 March 2016]. Available from https://www.cisco.com/web/learning/le21/le34/downloads/689/educause/ whitepaper.pdf

14. H. P. Utomo, A.T. Bon and M. Hendayun, "Academic Information System Support in the Era of Education 3.0", IOP Conf. Ser.: Mater. Sci. Eng., vol. 226, 2017.

15. A. Bhattacherjee, "Social Science Research: Principles, Methods, and Practices", USF Tampa Library Open Access Collections, 2012

16. S. Rose, N. Spinks and A. I. Canhoto, Management Research: Applying The Principles, United Kingdom: Routledge, 2014.

17. S. Kvale and S. Brinkmann, Interviews: Learning the craft of qualitative research interviewing. New York: Sage Publisher, 2009.

18. H.P. Utomo, A.T. Bon and M. Hendayun, SAMR As A Framework for Modeling of Academic Information System in Higher Education Institution toward Education 3.0", In Proc. of Int. Conf. on Glob. Opt. \& Its Apps. 2017

19. R. Puentedura, SAMR and TPCK: Intro to advanced practice, 2010 [cited 14 April 2017]. Available from http://hippasus.com/resources/sweden2010/ SAMR_TPCK_IntroToAdvancedPractice.pdf

20. C. B. Seaman, "Qualitative Methods In Empirical Studies of Software Engineering", IEEE Transaction on Software Enggineering, vol. 25, no. 4, pp. 557-572, 1999.

21. B. Marshall, P. Cardon, A. Poddar and R. Fontenot, "Does Sample Size Matter In Qualitative Research?: A Review of Qualitative Interviews In IS Research", Journal of Computer Information Sysstems, vol. 54, no. 1, pp. 11-22, 2013.

22. S.E. Baker, R. Edwards \& M. Doidge, "How Many Qualitative Interviews Is Enough?: Expert Voices And Early Career Reflections On Sampling and Cases In Qualitative Research", National Centre for Research Methods, Southampton, 2012.

23. R. K. Yin, Qualitative Research From Start To Finish, New York: Guilford Publications, 2011. 